\title{
Modeling of Wages and Prices Behavior: System Dynamic Approach
}

\author{
VALERIY KOZYTSKYY \\ Department of Mathematical Economics, Econometrics, Financial and Insurance Mathematics \\ Ivan Franko National University of Lviv \\ 1, Universytetska Str., Lviv, 79000 \\ UKRAINE
}

NELYA PABYRIVSKA

Department of Mathematics

Lviv Polytechnic National University

5 Mytropolyta Andreia Str., Lviv, 79007

UKRAINE

\author{
GALYNA BEREGOVA \\ Department of Computational Mathematics and Programming \\ Lviv Polytechnic National University \\ 5 Mytropolyta Andreia Str., Lviv, 79007 \\ UKRAINE
}

\begin{abstract}
The economies of almost every country in the whole word have been suffered from coronavirus pandemic consequences. The damage was especially hard for labor markets. The large magnitude of demand and production shocks that was caused by COVID-19 significantly disturbed the dynamics of output, wages and prices. The research problem addressed in this paper focuses on dynamic properties of wages and prices behavior influenced by shocks with different magnitudes and types. We apply a system dynamic approach to conduct the simulations of economic variables and investigate the possibility of their convergence to some stable path. We examine the impact of demand and production shocks on the output and prices as well as on wage and inflation behavior. It is proved that values of models parameters are crucial for existing of new steady state and convergence of economic variables. The paper determines the bifurcation points that separate different modes of transition period in moving towards or away from equilibrium. The research includes the investigation of the impact of economy's original state and emphasizes the importance of initial point of the system for the next its dynamics after shock. The research results derived in the paper serves as a useful learning tool to develop a discussion of the policy design issues related to reduction of negative impact of severe and unanticipated disturbance like COVID-19.
\end{abstract}

\section{Key-Words: - System Dynamics, Simulation Model, Wage, Price, Convergence, Equilibrium, Shocks}

Received: July 18, 2021. Revised: November 22, 2021. Accepted: December 22, 2021. Published: January 9, 2022.

\section{Introduction}

Nowadays the economies of almost every country in the whole word have been suffered from coronavirus pandemic consequences [1], [2]. The labor markets have been damaged especially hard [3]. In response to shocks, unemployment jumps sharply [4], the economic activity and production capability are extremely unstable [5]. Shopping preferences of consumers change not even in the structure of the consumer's good and services basket but also in the consumers' way of making shopping. Some part of enterprises were pushed into bankruptcy, the huge pool of labor force faced with a significant wage reducing or even became unpaid for an extended period of time, future appeared to be highly unpredictable and uncertain. The large magnitude of demand and production shocks that has been observed recently significantly disturbed the dynamics of output, prices and wages, hurt industrial enterprise [6], provoked unemployment [7], negatively affect the international trade [8] and interfered the socio-economic regional development [9]. Negative market disturbances have considerable and asymmetric impact not only on short-term dynamic behavior of labor force participation, unemployment, wages and inflation but can cause 
long-term negative impact with substantive nonlinear effect [10]. It is unpredictable if economic variables will reach a new steady state with balancing growth paths after shock as well as when they will achieve stabilization [11].

\section{Literature Review}

Danzer and Grundke (2020) examined the impact of labor demand shock caused by export prices on wages of workers. They revealed that shocks created incentives for agricultural sector to increase laborintensive production and emphasized that the competitive structures in local labor markets had important impact on wage evaluation in developing countries [12]. Bazhenova, Oliskevych and Lukianenko (2020) used a modern nonlinear econometric approach extended by regime switching technics to investigate the unemployment rate and labor force fluctuations in Eastern European countries. They proved the asymmetric and nonlinear impact of market shocks on their dynamics [13].

Lee, Yang, Kim and Kim (2018) studied the change in the supply and their impact on changes in prices. They focused on agricultural distribution network in Korea and developed a dynamic model describing the production fluctuation and the consumer's reaction on changes in product input and output flows through the adjustment of prices [14]. Other scientists found out that the evaluation of magnitudes and frequency of negative and positive economic shocks on labor market indicators is important factor of its economic [15].

In order to examine the dynamic of economic variables and their response on market shocks scientists estimated different types of econometric vector autoregressive models as well as used machine learning instruments. They developed models based on supervised and unsupervised learning [16], fuzzy logic approaches [17], predictive analytics and applications [18].

Zhu, Liao and Chen (2021) built a time-varying parametric VAR model with random fluctuations to examine the response of nonferrous metals industry in China on the uncertainty of the time-varying oil prices and economic policy [19]. Perez (2020) examine the effect of unexpected increase in the real wage in formal and informal sectors. Based on combined unconditional quantile regressive models with a differences-in-differences structure, researcher suggested the reasons of wage exposure to the shocks and emphasized the importance of wages close to the minimum wage changes in Colombia [20].

Oduyemi and Owoeye (2020) investigated the dynamics of oil prices and showed that in oil exporting countries the reliance of government finance on oil revenue put in risk the income stability and had an impact on development of human capital [21]. Kaminskyi, Nehrey and Komar (2020) developed a complex approach to analyze risks of investment in Exchange Trade Funds of agriculture. They applied general portfolio ideas extended by different conceptual taking into account specific characteristics of agricultural investments and estimation of shocks in probability [22].

The researches also estimated the long-run equilibrium relationships between economic variables in combination with their short-term dynamic fluctuating behavior. It was proved the existence of adjustments forces that influenced fuel consumption to converge to the stable trajectories [23]. Bielinskyi et al. (2021) proved the inadequacy of the quantitative approach for pricing processes evaluation and received the evidences for instability of the price dynamics on the energy market that can produce severe shocks and crashes [24].

\section{Methodology}

The research paper focuses on the dynamic of prices and output fluctuations in response to market shocks that disturb the economic activity. Our purpose is to analyze output and price adjustments and to create model that describes their behavior in transitory period and steady state. Suppose, $Y$ - the total output of firms; $y$ - the total output of firms that correspond to the flexible-price or natural level of output; $L-$ labor force; $l$ - labor force surplus; $p$ - price level; $w$ wage; $\pi$ - inflation. Suppose the production function, $Y=F(L)$, is a twice differentiable and invertible function and $L=F^{-1}(Y)=f(Y), f^{\prime}(Y)>0$. The equilibrium price level, $p^{e}$, is described as a marginal wage cost and is determined by $f(Y)$. Therefore, $p^{e}=$ $f^{\prime}(Y)$. The equilibrium aggregate demand, $G\left[p^{e}, f\left(Y^{e}\right)\right]$ that depends on equilibrium price level and labor is equal to supply $Y^{e}$, so output gap $y$, labor force surplus $l$ and inflation $\pi$ are zero.

In the short term, we observe price and output fluctuations with adjustments

$$
\begin{aligned}
p^{\prime} & =\mu(G(p, f(Y))-Y), & \mu & >0, \\
Y^{\prime} & =\lambda\left(p-f^{\prime}(Y)\right), & & \lambda>0 .
\end{aligned}
$$

Then the model extend by equations

$$
f^{\prime}(Y)=\alpha_{0}+\alpha_{1} Y+\alpha_{2} Y^{2}+\varepsilon_{Y}
$$

$G(p, f(Y))=\beta_{0}+\beta_{1} p+\beta_{2} p^{2}+\beta_{3} p^{3}+\gamma_{1} Y+\gamma_{2} Y^{2}+\varepsilon_{p}$, (4) where $\varepsilon_{Y}, \varepsilon_{p}$ are assumed to be independent whitenoise processes.

Next, we denote $g w$ - the short-run deviation between the long run desired real wage and actual real wage; $g \pi$ - deviation of actual inflation and natural long run expected inflation. For simulation of real wage and inflation behavior, we use a system 
dynamics model that is described by system of firstorder differential equations

$$
\begin{gathered}
g w^{\prime}=\pi, \\
g \pi^{\prime}=\eta g \pi-g w-\eta g w^{2} g \pi
\end{gathered}
$$

and can be represented by a second-order equation

$$
g w^{\prime \prime}-\eta\left(1-g w^{2}\right) g w^{\prime}+g w=0 .
$$

We take various initial points of system and discover how the dynamics of wage and inflation depends on value of parameter $\delta$. It is important to establish the set of $\delta$ where the variables reach the equilibrium and to investigate if the equilibrium is stable.

\section{Results and Discussion}

The initial points of system (1) - (4) variables and value of models' parameters that evaluated sensitiveness have important impact on simulation results and dynamics of system.

The change in parameter $\lambda$ that determine the level of output sensitivity have significant impact on behavior of output and price during the business cycles (Fig. 1, 2). Strong sensitivity of output production to the deviation between price and marginal wage cost leads to more visible oscillation in short term whereas in the long term the output capability stabilizes. The level of new stable state depends on magnitude of shock. In case of a strong negative shock, the output drops significantly and does not return to the original level. The price dynamics shows decreasing behavior that corresponds to recession of market activity.

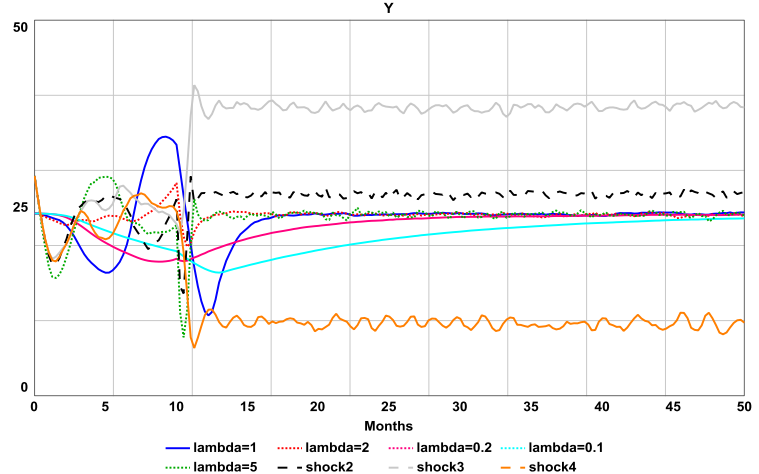

Figure 1: The output dynamics for different level of production capability adjustment after shock

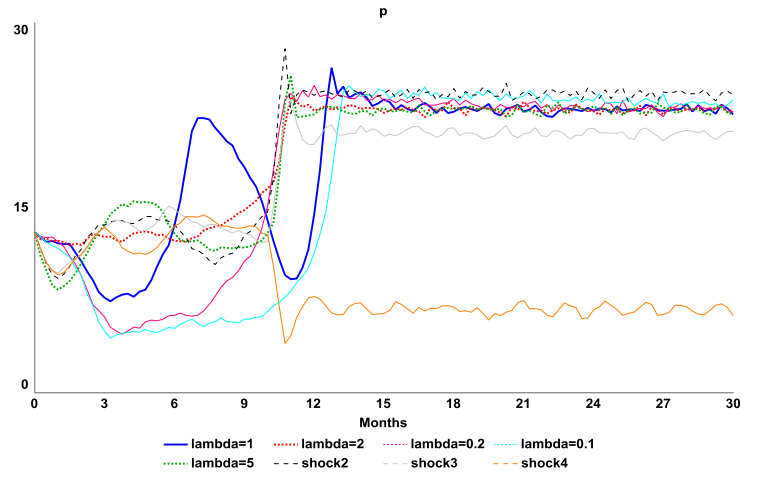

Figure 2: The price dynamics for different level of production capability adjustment after shock

In case of a strong negative shock (Fig. 3, orange points set), the output drops significantly and does not return to the original level. The price dynamics shows decreasing behavior that corresponds to recession of whole market activity. Eventually the economics reach the new stable position with lower output and lower price index.

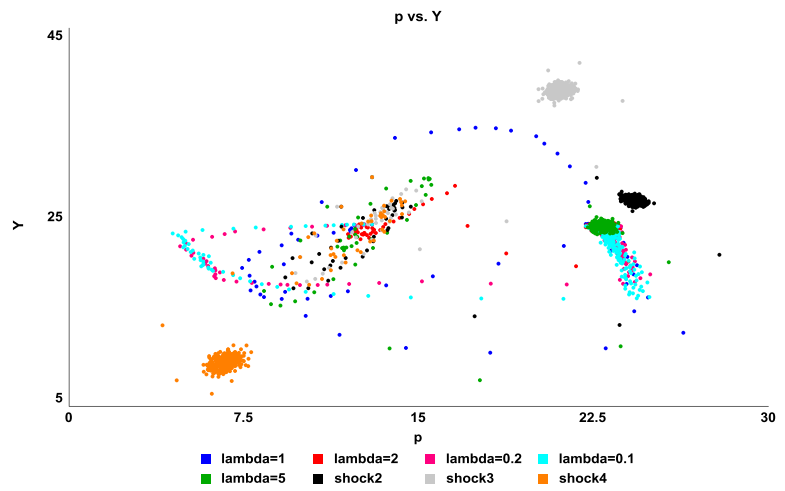

Figure 3: Convergence of output and price level for different level of production capability adjustment after shock

The simulation of model for different combination of both sentitivity coefficients are shown in Fig. 4, 5, 6. We take both adjustments coefficients less that 1 so they characterize weak response of variables to both demand and supply discrepancies. However, the dynamics reveals to be quite different even for small changes in parameters of model. The adjustemnt is not quick, the respose to shocks are rather cautious. The market needs some time to adjust to new market condition even for small value of price and output sensitivities. 


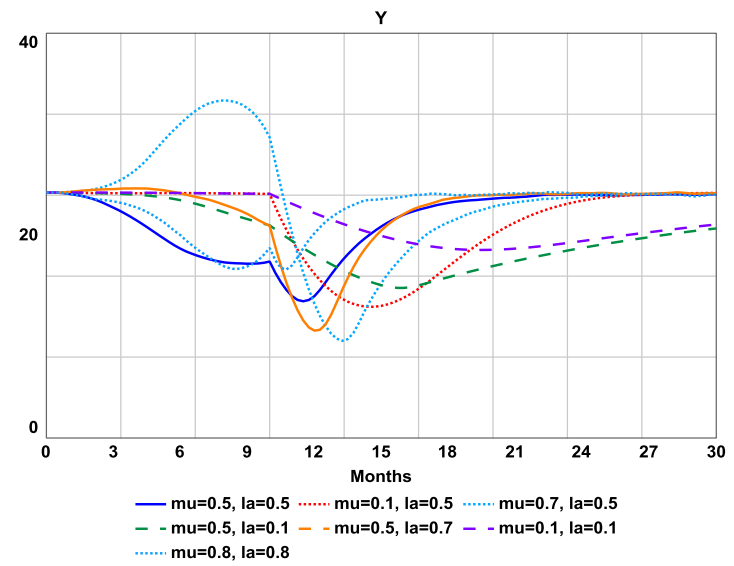

Figure 4: The impact of change in demand and production adjustment coefficients combination on output dynamics

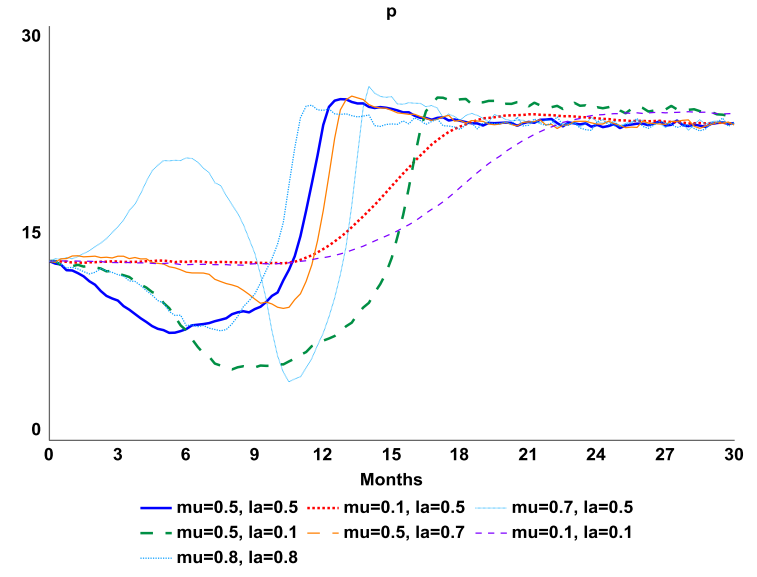

Figure 5: The impact of change in demand and production adjustment coefficients combination on price dynamics

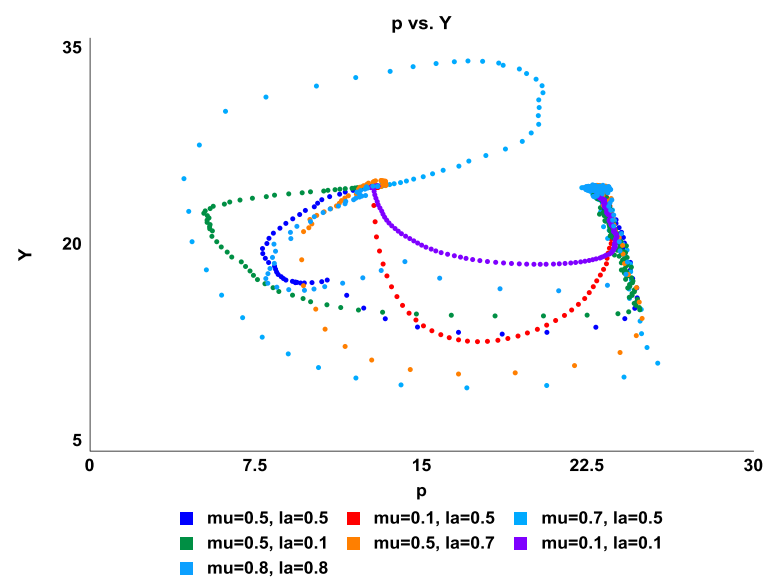

Figure 6: The impact of change in demand and production adjustment coefficients combination on convergence pattern

For model (5)-(6) variables, the transition period varies depending on starting market conditions.
In case when $\delta$ is less than -2 , the wage gap and inflation eventually stabilize and reach the equilibria (Fig. 7).

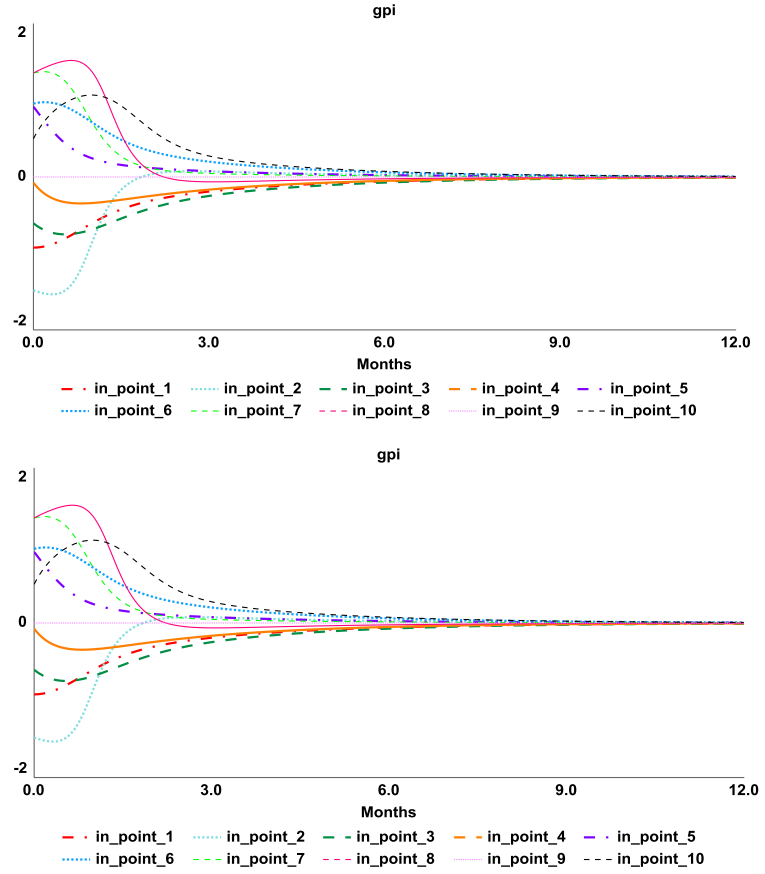

Figure 7: The dynamics of wage and inflation from different initial points for $\delta=-3$

When $\delta$ belong to the interval $(-2 ; 0)(-2<\delta<0)$ the equilibrium point is still steady (Table 1$)$.

Table 1: The simulation results for wage and inflation gaps in cases of stable focus

\begin{tabular}{|c|c|c|c|}
\hline \multirow{3}{*}{$\begin{array}{l}\text { Value of } \\
\text { parameter }\end{array}$} & \multirow{3}{*}{ Time } & Inflation gap & Wage gap \\
\hline & & \multicolumn{2}{|c|}{$\begin{array}{l}\text { Initial value } \\
\end{array}$} \\
\hline & & $\mathrm{gpi}_{0}=0.3$ & $\mathrm{gW}_{0}=1.3$ \\
\hline \multirow[t]{15}{*}{$\delta=-1.5$} & 1 & 0.6641 & -1.0604 \\
\hline & 2 & -0.0667 & -0.3568 \\
\hline & 3 & -0.2062 & 0.0146 \\
\hline & 4 & -0.1374 & 0.0933 \\
\hline & 5 & -0.0548 & 0.0648 \\
\hline & 6 & -0.0097 & 0.0267 \\
\hline & 7 & 0.0050 & 0.0053 \\
\hline & 8 & 0.0059 & -0.0020 \\
\hline & 9 & 0.0032 & -0.0027 \\
\hline & 10 & 0.0011 & -0.0015 \\
\hline & 11 & 0.0001 & -0.0005 \\
\hline & 12 & -0.0002 & -0.0001 \\
\hline & 13 & -0.0002 & 0.0001 \\
\hline & 14 & -0.0001 & 0.0001 \\
\hline & 15 & 0.0000 & 0.0000 \\
\hline
\end{tabular}

However, the dynamics of variables as well as the shape of phase diagram are very distinguish (Fig. 8) from the first case when $\delta$ is less than -2 . 


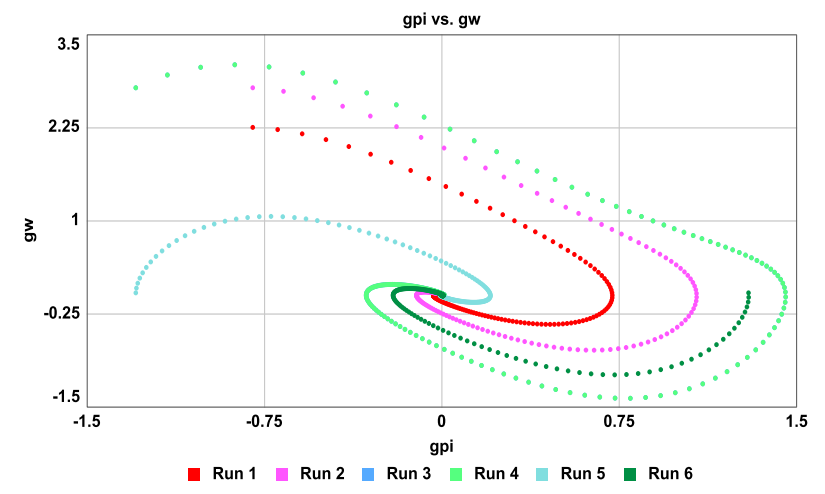

Figure 8: The stable focus convercence $(\delta=-1.5)$ of wage and inflation to equilibrium from different initial points

If $\delta$ equals zero the behavior of the system variables changes dramatically and follows a circle (Table 2).

Table 2: The simulation results for wage and inflation gaps in cases of circle

\begin{tabular}{|c|c|c|c|}
\hline \multirow{3}{*}{$\begin{array}{l}\text { Value of } \\
\text { parameter }\end{array}$} & \multirow{3}{*}{ Time } & Inflation gap & Wage gap \\
\hline & & \multicolumn{2}{|c|}{ Initial value } \\
\hline & & $\mathrm{gpi}_{0}=-0.5$ & $\mathrm{gw}_{0}=0.5$ \\
\hline \multirow[t]{15}{*}{$\delta=-1$} & 1 & $\begin{array}{ll}-0.0412 \\
\end{array}$ & 0.3440 \\
\hline & 2 & 0.1584 & 0.0650 \\
\hline & 3 & 0.1397 & -0.0779 \\
\hline & 4 & 0.0500 & -0.0851 \\
\hline & 5 & -0.0129 & -0.0373 \\
\hline & 6 & -0.0286 & 0.0024 \\
\hline & 7 & -0.0176 & 0.0157 \\
\hline & 8 & -0.0032 & 0.0114 \\
\hline & 9 & 0.0040 & 0.0031 \\
\hline & 10 & 0.0043 & -0.0018 \\
\hline & 11 & 0.0019 & -0.0026 \\
\hline & 12 & -0.0001 & -0.0013 \\
\hline & 13 & -0.0008 & -0.0001 \\
\hline & 14 & -0.0006 & 0.0004 \\
\hline & 15 & -0.0002 & 0.0004 \\
\hline
\end{tabular}

If $\delta$ becomes a positive value the fixed point is no longer stable (Fig. 9) and the phase diagram is no longer a circle (Fig, 10).

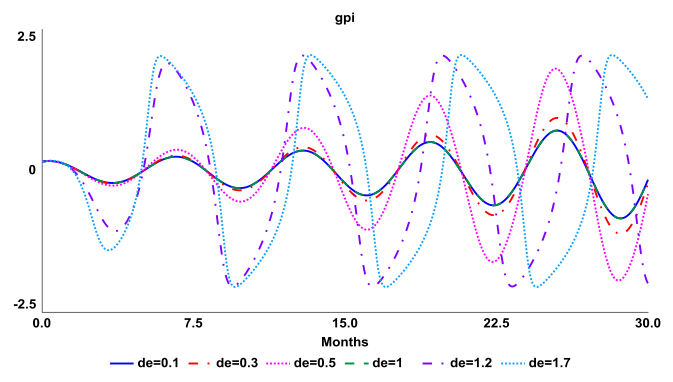

Figure 9: The inflation gap behavior moving away from equilibrium poit for different value of $\delta$ in case of unstable focus

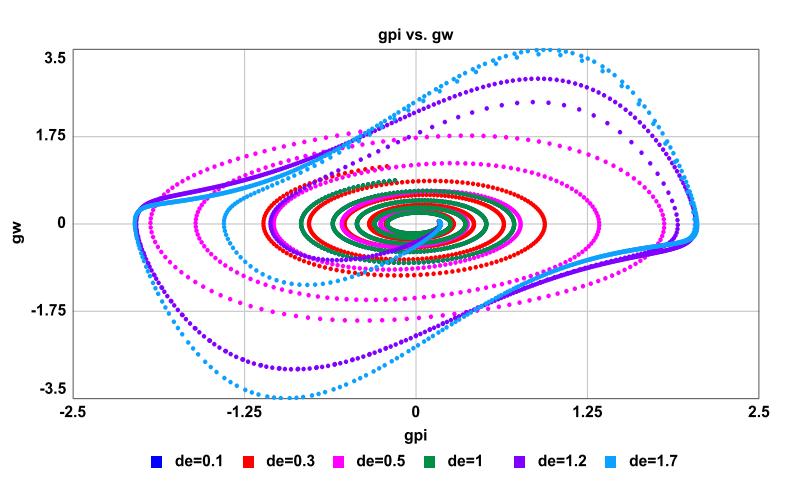

Figure 10: Pathes of wages and prices moving away from equilibrium, unstable focus behavior

\section{Conclusion}

The impact of shocks produced by the COVID-19 is difficult to predict. It is even hard to establish with reasonable accuracy whether economies will converge to some new stable states like there were before the start of the pandemic or they will move in some other uncertain directions. The research provided in the paper shows that next behavior of output, wages, prices and inflation after the shock very depends on the initial state of economics that was inherent for the particular country before shock. The parameters of economies' functioning, sensitivity of wages and prices to demand and output capability changes have even more determining effect. It was revealed the existence of two types of bifurcations that created dynamics about a stable path or around unstable point. The different magnitudes of cycles suddenly appeared as an outcome of changes in model's parameters. The economic systems could exhibit multiple equilibria and jump from one to another stable equilibrium if market susceptibility varied. The research results derived in the paper serves as a useful learning tool to develop a discussion of the policy design issues related to reduction of negative impact of severe and unanticipated disturbance like coronavirus pandemic.

\section{References:}

[1] Mahmud, Appel, Donghong Ding and Md. Morshadul Hasan, "Corporate Social Responsibility: Business Responses to Coronavirus (COVID-19) Pandemic," SAGE Open, Vol. 11(1), 2021, 21582440209.

[2] Hryhoruk, Pavlo, Nila Khrushch, Svitlana Grygoruk, Kateryna Gorbatiuk and Liudmyla Prystupa, "Assessing the impact of covid-19 pandemic on the regions' socio-economic development: The case of Ukraine," European Journal of Sustainable Development, Vol. 10(1), 2021, pp. 63-80. 
[3] Pantelimon, Florin-Valeriu, Bogdan-Stefan Posedaru, Elena-Aura Grigorescu and DimitrieDaniel Placinta, "Labor Market Trends During The COVID-19 Pandemic," Informatica Economica, Academy of Economic Studies Bucharest, Romania, Vol. 25(2), 2021, pp. 5063.

[4] Oliskevych, Marianna and Iryna Lukianenko, "European unemployment nonlinear dynamics over the business cycles: Markov switching approach," Global Business and Economics Review, Inderscience Publishers, Vol. 22, Issue 4, 2020, pp. 375-401.

[5] Guryanova, Lidiya, Olena Bolotova, Vitalii Gvozdytskyi and Olena Sergienko, "Long-term financial sustainability: An evaluation methodology with threats considerations," Rivista di Studi sulla Sostenibilita, Vol. 2020(1), 2020, pp. 47-69.

[6] Matviychuk, Andriy, Oleksandr Novoseletskyy, Serhii Vashchaiev, Halyna Velykoivanenko and Igor Zubenko, "Fractal analysis of the economic sustainability of industrial enterprise," in CEUR Workshop Proceedings, 2422, 2019, pp. 455466.

[7] Lukianenko, Iryna and Marianna Oliskevych, "Evidence of Asymmetries and Nonlinearity of Unemployment and Labour Force Participation Rate in Ukraine," Prague Economic Papers, Vol. 26, Issue 5, 2017, pp. 578-601.

[8] Hayakawa, Kazunobu and Hiroshi Mukunoki, "The impact of COVID-19 on international trade: Evidence from the first shock," Journal of the Japanese and International Economies, Elsevier, Vol. 60(C), 2021, Article 101135.

[9] Hryhoruk, Pavlo, Nila Khrushch and Svitlana Grygoruk, "Using multidimensional scaling for assessment economic development of regions," International Journal of Industrial Engineering and Production Research, Vol. 31(4), 2020, pp. 597-607.

[10] Oliskevych, Marianna and Iryna Lukianenko, "Labor Force Participation in Eastern European Countries: Nonlinear Modeling," Journal of Economic Studies, Emerald Publishing, Vol. 46, No. 6, 2019, pp. 1258-1279.

[11] Skrypnyk, Andriy and Maryna Nehrey, "The formation of the deposit portfolio in macroeconomic instability," in CEUR Workshop Proceedings, 1356, 2015, pp. 225235.

[12] Danzer, Alexander and Robert Grundke, "Export price shocks and rural labor markets: The role of labor market distortions," Journal of
Development Economics, Elsevier, Vol. 145(C), 2020.

[13] Bazhenova, Olena, Marianna Oliskevych and Iryna Lukianenko, "Regime Switching Modeling of Unemployment Rate in Eastern Europe," Journal of Economics, Institute of Economic Research of Slovak Academy of Sciences, Vol. 68, Issue 4, 2020, pp. 380-408.

[14] Lee, Daekyung, Seong-Gyu Yang, Kibum Kim and Beom Jun Kim, "Product flow and price change in an agricultural distribution network," Physica A: Statistical Mechanics and its Applications, Elsevier, Vol. 490(C), 2018, pp. 70-76.

[15] Oliskevych, Marianna and Viktor Tokarchuk, "Dynamic modelling of nonlinearities in the behavior of labor market indicators in Ukraine and Poland," Economic Annals - XXI, Vol. 169, Issue 1-2, 2018, pp. 35-39.

[16] Babenko, Vitalina, Andriy Panchyshyn, Larysa Zomchak, Maryna Nehrey, Zoriana ArtymDrohomyretska and Taras Lahotskyi, "Classical Machine Learning Methods in Economics," WSEAS Transactions on Business and Economics, vol. 18, Art. \#22, 2021, pp. 209217.

[17] Matviychuk, Andriy, "Fuzzy logic approach to identification and forecasting of financial time series using Elliott wave theory," Fuzzy Economic Review, Vol. 11(2), 2006, pp. 51-68, 2006.

[18] Guryanova, Lidiya, Roman Yatsenko, Nadija Dubrovina and Vitalina Babenko, "Machine learning methods and models, predictive analytics and applications," in CEUR Workshop Proceedings, 2649, 2020, pp. 1-5.

[19] Zhu, Xuehong, Jianhui Liao and Ying Chen, "Time-varying effects of oil price shocks and economic policy uncertainty on the nonferrous metals industry: From the perspective of industrial security," Energy Economics, Elsevier, Vol. 97(C), 2021, Article 105192.

[20] Pérez, Jorge Pérez, "The minimum wage in formal and informal sectors: Evidence from an inflation shock," World Development, Elsevier, vol. 133(C), 2020.

[21] Oduyemi, Gabriel and Taiwo Owoeye, "Oil Price Fluctuation and Health Outcomes in an Oil Exporting Country: Evidence from Nigeria," International Journal of Energy Economics and Policy, Econjournals, vol. 10(4), 2020, pp. 212-220.

[22] Kaminskyi, Andrii, Maryna Nehrey and Mariana Komar, "Complex Risk Analysis of Investing in Agriculture ETFs," International 
Journal of Industrial Engineering \& Production Research, vol. 31 (4), 2020, pp. 579-586.

[23] Oliskevych, Marianna, Galyna Beregova and Viktor Tokarchuk, "Fuel Consumption in Ukraine: Evidence from Vector Error Correction Model," International Journal of Energy Economics and Policy, Vol. 8(5), 2019, pp. 58-63.

[24] Bielinskyi, A., I. Khvostina, A. Mamanazarov, A. Matviychuk, S. Semerikov, O. Serdyuk, V. Solovieva and V. Soloviev, "Predictors of oil shocks, Econophysical approach in environmental science," in IOP Conference Series: Earth and Environmental Science, Vol. 628(1), 2021, 012019.
Contribution of individual authors to the creation of a scientific article (ghostwriting policy)

All authors have equally contributed to the paper.

\section{Creative Commons Attribution}

\section{License 4.0 (Attribution 4.0}

\section{International, CC BY 4.0)}

This article is published under the terms of the Creative Commons Attribution License 4.0 https://creativecommons.org/licenses/by/4.0/deed.en US 